\title{
Investigating the Relationship between Knowledge Sharing Strategies and Organizational Excellence Pillars
}

\author{
Abeer Hmoud AL-Faouri ${ }^{1}$, Subhasish Dasgupta ${ }^{2}$ \\ and Mohammed Mufaddy Al-Kasasbeh ${ }^{3}$ \\ ${ }^{1}$ Management Information Systems Dept., Al-Balqa' Applied University, Jordan \\ ${ }^{2}$ Information Systems \& Technology Management Dept., George Washington University, USA \\ ${ }^{3}$ Police College, Abu Dhabi, UAE
}

\begin{abstract}
Although it is generally accepted that only organizations with a commitment to knowledge sharing and organizational excellence will remain competitive, there are an alarmingly low number of public organizations that have been identified as having the basics of excellence in the fourth cycle (2008/2009) of King Abdullah II Award for Excellence in Government Performance and Transparency in Jordan. It is then the aim to perform a study that seeks to investigate the relationship between codification and personalization knowledge sharing strategies on three main pillars of organizational excellence which were adapted by the award. These pillars include: customer focus, results orientation and transparency.
\end{abstract}

Survey method employing a questionnaire as a technique for collecting data was used. The survey involves four selected government organizations who won the award in the fourth cycle (2008/2009) and are familiar with the topic of this study. 500 questionnaires were distributed using the simple random sampling technique yielding to 191 usable responses. The data collected was analyzed using SPSS version 15. To ensure the validity and reliability of the instrument, factor analysis and reliability test were performed. Analysis revealed that there are positive and significant relationships between codification and personalization knowledge sharing strategies and each of the organizational excellence pillars. The results of multiple regression analyses indicated that codification knowledge sharing strategies is a more significant predictor of each organizational pillar than personalization knowledge sharing strategies. The results of this study could encourage public organizations in adopting knowledge sharing strategies to enhance their organizational excellence.

Keywords: Codification Knowledge Sharing Strategy, Personalization Knowledge Sharing Strategy, Organizational Excellence, King Abdullah II Award for Excellence in Government Performance and Transparency in Jordan

\section{Introduction}

In the "resource-based" view of the firm, knowledge is considered to be the most strategically important resource (Hu, 2009) within the current business environment. Therefore, an organization's success in achieving competitive advantage to a great

Copyright (C) 2011 Abeer Hmoud AL-Faouri, Subhasish Dasgupta and Mohammed Mufaddy Al-Kasasbeh. This is an open access article distributed under the Creative Commons Attribution License unported 3.0, which permits unrestricted use, distribution, and reproduction in any medium, provided that original work is properly cited. Contact author: Abeer Hmoud AL-Faouri E-mail: abeerfa2001@yahoo.com 
extent depends on its capability to produce value from its knowledge resources (Steyn \& Kahn, 2008; Eftekharzadeh, 2008; Drucker, 1993).

There is no agreed definition of knowledge management (KM) even among practitioners, (Ortiz et al., 2004) because academic researchers and practitioners in various fields tend to define the concept of knowledge based upon their own particular fields and interests (Behery, 2008). Some view $\mathrm{KM}$ as the management of processes that enable the movement of knowledge into, through and out of the organization with the ultimate aim of enhancing organizational efficiency and performance (Firestone \& McEllroy, 2005; Darroch, 2003). Fatt et al. (2010) view KM as "a tool by which the organization's core competencies can be focused and developed". UNDP pioneers and the World Bank have used this tool widely in their operations (Ortiz et al., 2004). KM can succeed only with knowledge sharing.

In the literature, it is generally accepted that knowledge sharing is the single most important factor in firm performance $(\mathrm{Hu}$, 2009; Nonaka and Takeuchi, 1995) and the value of $\mathrm{KM}$ that must be nurtured and articulated (Kleinschmidt, 2009; Steyn \& Kahn, 2008; Osborne, 2004). Knowledge sharing occurs when an individual is willing to learn from others (Yang, 2007) and to diffuse relevant information across the organization (Hu, 2009). Unfortunately, organizations often waste their resources repeating the same mistakes, duplicating projects and being unaware of one another's knowledge (Eftekharzadeh, 2008). Therefore, it is crucial for the organizations to establish a clear and structured KM strategy as a prerequisite for knowledge sharing and dissemination both internally and externally (Steyn \& Kahn, 2008; Ortiz et al., 2004). This is especially important since knowledge can be explicit (data, manuals, procedures, etc) or tacit/implicit. Besides that, the world's economy transformation into a service economy, which is more often social and rarely science-based or technological in nature, requires a new way to access both customers (Hu, 2009) and employeesespecially frontline workers who are the most-knowledgeable and the primary actors (Frazier \& Swiss, 2008).

The Award of King Abdullah II for Excellence in Government Performance and Transparency was established in September 2002 in Jordan by a Royal Decree. The ultimate goal of establishing the award is to enrich the culture of excellence by increasing the awareness of distinguished performance concepts, quality and transparency (Award website, 2010). The criteria of the award measure the public sector adoption of three excellence pillars: customer focus, results orientation and transparency. Knowledge criterion is one of the award's criteria. Among the aspects the latter criterion assesses are to what extent the public organizations are committed to manage knowledge and raise awareness of its importance, proper planning and implementation of KM and knowledge (Award Guide, 2009).

There are an alarmingly low number of public organizations that have been identified as having the basics of excellence in the fourth cycle (2008/2009) of the award in Jordan. Neither the Golden phase award, nor the Silver phase has been won, but only Bronze phase award has been won by the researched organizations. This leaves the impression that the majority of organizations are performing below this expectation. This is simply not good enough when dealing with citizens who deserve the best possible excellent services. It is then the aim to perform a study to investigate the influence of knowledge sharing strategies on organizational excellence $\mathrm{OE}$ pillars in the winning public organizations of the award in the fourth cycle $(2008 / 2009)$. The remainder of the paper proceeds as follows. The next section considers the relevant literature and sets out the hypotheses of this study. Following is the study's methodology. Then, the results of this empirical study, discussion and conclusions are presented in the last 
section. The paper closes with an outlook on further research opportunities and some managerial implications.

\section{Literature Review and Hypotheses Development}

In this section, a brief review of earlier research on knowledge sharing strategies, the researched OE pillars -customer focus, results orientation, transparency and the influence of knowledge sharing strategies on each of these pillars will be provided. Then we will try to derive the hypotheses of this study.

\section{Knowledge Sharing Strategies}

A review of prior related literature uncovers many classifications for knowledge sharing strategies. Some mentioned that the most common approaches to KM seem to be technology-oriented and/or people-oriented (Saito et al., 2007), content perspective and/or relational perspective (Hayes and Walsham, 2003), the object (product, stock) perspectives on knowledge and/or the process (flow) perspectives on knowledge (Alavi and Leidner, 2001; Mentzas et al., 2001), KM of infrastructure and processes and/or KM of the people (Sunassee and Sewry, 2002), Codification (system) and/or personalization (human) strategies for KM (Hansen et al., 1999; Choi and Lee, 2002), and technocratic schools and/or behavioral schools of KM (Earl, 2001). As the different classifications are similar in their main propositions of each strategy type, in this study, we adopted the codification and/or personalization classification of knowledge sharing strategies. Following is a brief review of codification knowledge sharing strategy and personalization knowledge sharing strategy concepts.

\section{Codification of Knowledge Sharing $\underline{\text { Strategies }}$}

Codification strategy is about turning tacit knowledge into explicit knowledge (Fatt et al., 2010; Hansen et al., 1999), and is known as people-to-document approach (Hansen et al., 1999). It is technology-oriented; emphasizing the explicit nature of knowledge (Saito et al., 2007). It involves securing knowledge then storing it in databases, which comprise white papers, approach notes, case studies and best practice documents prepared by employees of the organization based on their experience or insights, (Mukherji, 2005) for others to access and reuse when the product or service in question is regular or established (Smith, 2004).

Information and communication technology (ICT) use and knowledge sharing are closely linked (Lin, 2007) because ICT can be effectively used to facilitate the codification (Song, 2002) and sharing of organizational knowledge within internal entities (Huysman and Wulf, 2006; Awad and Ghaziri, 2004), allowing firms to achieve more effective collaborative activities (Pan and Leidner, 2003) to maximize the added-value that ICT can bring to them (Dalkir, et al., 2007).

The construct "Codification Knowledge Sharing Strategies" CKSS is the first independent variable in this study. It is measured by (1-7) questionnaire items which were developed based on prior studies (such as Fatt et al., 2010; Al-Faouri, 2010; Mukherji, 2005; Nonaka et al., 2001; Hansen et al., 1999).

\section{Personalization Knowledge Sharing Strategies}

Personalization strategy emphasizes the tacit nature of knowledge (Fatt et al., 2010; Hansen et al., 1999). Knowledge sharing is not simply ICT usage (Song, 2002), but follows a people-to-people approach and focuses on dialogue and the relationships within the social unit of the organization (Chaung, 2004). So, it is context-dependent process of understanding which requires human communication and cognition in order to emerge (Saito et al., 2007). Therefore, the ability of employees to share knowledge depends first and foremost on 
their communication skills (Riege, 2005; Davenport and Prusak, 1998; Meyer, 2002). Besides that, companies with greater collaborative experience benefit more from tacit knowledge transfer (Alwis \& Hartmann, 2008). So the second variable in this study is "Personalization Knowledge Sharing Strategies" PKSS. It is measured by (8-14) questionnaire items which were developed based on prior studies (such as Fatt et al., 2010; Al-Faouri, 2010; Mukherji, 2005; Nonaka et al., 2001; Hansen et al., 1999).

\section{Organizational Excellence Pillars}

Only companies with a commitment to organizational excellence and surpassing or outstanding achievement will remain competitive (Srivastava et al., 2008). In the award guide (2009), excellence is defined as "achieving and maintaining distinguished performance levels which not only fulfill the requirements of all the stakeholders but also exceed them". Reviewing literature reveals different perspectives related to OE pillars exist. For example, Hesselink and Assem (2002) declare that a chain starts with excellent leadership that creates excellent employees who provide excellent service to the customers who will then come, which leads to good financial results. McKinsey \& Company, Inc. used leadership, work environment \& employee interaction, coordination, innovation, direction and external orientation areas to underline organizational excellence (De Smet, 2007). Baldridge criteria (2010) of performance excellence are based upon several characteristics that include: leadership, strategic planning, customer focus, measurement, analysis, knowledge management, workforce focus, process management and results. The King Abdullah II Award adopts three main excellence pillars: customer focus $\mathrm{CF}$, results orientation RO and transparency TR (Award guide, 2009). These pillars are adopted in this study to explore the influences of KS strategies on them.
Basically, the statements that measure each of the dependent variables were developed based on their presented definitions in the Award guide, which were originally formulated based on global models and standards, such as European Foundation for Quality Management (EFQM), Excellence Model 2010, Malcolm Boldrige Excellence Model (USA) and International Standard Organization (ISO) 9000: 2000 (E) (Award guide, 2009). Besides that, the forms which are used to fulfill the requirements of the award, such as customer satisfaction form, RADAR methodology form, mystery shopper form were also reviewed and considered when developing the statements (for more information about these forms please visit the Award website: http://www.kaa.jo/Award). Additional items were also developed based on the related previous studies as will be clarified in the following sections.

Knowledge Sharing Strategies and Customer Focus as an Organizational Excellence Pillar

According to Drucker (1954), satisfying customers is the true mission of a business which yields profits and other rewards. Srivastava et al., (2008) argue that the organization that effectively meets the expectations of all stakeholders is an excellent organization. Customer focus and satisfaction is also viewed as primary determinant of performance excellence (Day, 2003) and a key performance indicator in many frameworks, such as the balanced scorecard framework (Rhodes et al., 2008), Skandia Navigator (Skandia, 1994), etc. Therefore, tools with a customer orientation should receive the greatest attention (Frazier \& Swiss, 2008) to develop deeper knowledge-enabled relationships (Riege, 2005; Schotte, 2003).

In the Award guide (2009), the customer is defined as any person or agent to whom the service is provided by the public 
organization. Customer satisfaction is also defined as the opinion of the service recipient about fulfilling his requirements, needs and expectations (Award guide, 2009). So a customer focus is the firm-level ability to identify, analyze, understand and meet customer needs (Deshpande et al., 1993; Gatignon and Xuereb, 1997). "Customer focus" CF is the first OE pillar in the Award and the first dependent variable in this study. Items (15-22) in the questionnaire were used to measure this construct and were primarily developed based on the definition presented in the Award guide (2009), customer satisfaction form and the related reviewed studies (Ferrell et al., 2010; Nakata et al., 2008; Ailawadi et al. 2009; Bigné, et al., 2008).

Ferrell et al., (2010) suggest that research on best practices and the role of technology in advancing direct selling industry could have social significance, particularly in developing countries. Widén-Wulff and Suomi, (2007) mentioned that the common aim and purpose of sharing is to fulfill customer needs. Others added that sharing information changes the dynamics of service provisioning and subsequent evaluation of its effectiveness and reduces conflicts (Sen et al., 2010).

Some researchers have hypothesized that customer focus is strengthened by IT capability (Nakata et al., 2008), because IT capability can assist in sharing customer data and can aid decision-making, problemsolving and planning based on customer information (Nakata et al., 2008). According to Ferrell et al. (2010), technology appears to be emerging as a strategic concern for creating and managing consumer relationships. Other literature indicates that the investment in technology tools such as CRM applications will benefit firms and their sales representatives financially (Rapp, Agnihotri, and Forbes 2008). As a result more service industries are focusing attention on sales technologies as a way to enhance and to ensure long-term businessto-consumer relationships (Ailawadi et al.
2009; Bigné, et al., 2008). Accordingly, the first hypothesis of this study proposes that:

H1: A positive significant relationship exists between codification knowledge sharing strategy and customer focus.

Reviewing social rule systems literature uncovered that positive social elements such as trust or other elements are key enablers of customer focus (Nakata et al., 2008; Lee and Choi, 2003; Tillquist, 2000). Shibata \& Kodama (2007) found that the use of a network of strategic communities including customers, made it possible for the development process of new numerical control systems to occur at a speed not yet known in the world. They also found that forming internal informal cross-functional teams holding appropriate informal meetings and dynamically sharing knowledge customers fosters the sharing of new knowledge that responds to customers needs in a timely manner (Shibata \& Kodama, 2007). Hence, we propose the following second hypothesis:

H2: A positive significant relationship exists between personalization knowledge sharing strategy and customer focus.

Knowledge Sharing Strategies and Results
Orientation as an Organizational
Excellence Pillar

Over the last two decades, the philosophy of management in governments worldwide has incorporated private sector management techniques (Pollitt \& Bouckaert, 2000). To create public value, executives were called to become "results-based managers" and to introduce managerial accountability for program outcomes (Try \& Radnor, 2007; Moore, 1995). Results-orientation was viewed as a comprehensive, life cycle approach to management that integrates business strategy, people, processes and measurements to improve decision-making (The Treasury Board of Canada, 2003). Utilizing this approach enables an organization to ensure that its processes, 
products and services are contributing to the attainment of its objectives, through the monitoring of a set of indicators and the reporting of performance data to its managers (Try \& Radnor, 2007). So the second dependent variable in this study is "Results orientation". It is adopted because of the importance it gained in many public and nonprofit organizations. Items (23-28) in the questionnaire were used to enable the respondents of this study to assess how well their organizations are results oriented. These items were developed based on reviewing the presented definition for results orientation by the Award guide (2009) and the RADAR methodology- an evaluation tool used in the (EFQM) excellence model and can be also used to conduct self assessment form. The previous items were also developed based on related previous studies (such as Huang \& Li, 2009; Frazier \& Swiss, 2008; Try \& Radnor, 2007).

Ortiz et al. (2004) mentioned that the growing awareness about the need for KM as a key management support tool can be used to reinforce and complement RO. Riege (2005) assures that knowledge sharing practices can assist in optimizing business goals. Try \& Radnor (2007) found that the absence of timely performance information is a core limitation to results- based management. Others argue that when knowledge can be disseminated effectively, organization members are more inclined to utilize knowledge to achieve favorable results (Huang \& Li, 2009).

Broadbent et al. (2003) point out that IT systems enable firms to increase work efficiencies. Ortiz et al. (2004) propose that organizations planning to implement $\mathrm{KM}$ and RO need to develop a long term IT strategy to contemplate the existing synergies between the two concepts (Ortiz et al., 2004). Others argue that computers present no meaningful gains due to their ubiquity and commodity nature (Carr, 2003; Brynjolfsson and Hitt, 2000; Dedrick et al., 2003). Singh \& Zollo (1998) also indicate that the positive relationship between codification and performance was not supported. Therefore, this debate is a reminder that the contribution of IT capability to business performance is not entirely settled which gives us another justification to conduct such a study. Accordingly, the following hypothesis is formulated:

H3: A positive significant relationship exists between codification knowledge sharing strategy and results orientation.

On the other hand, the need to develop an appropriate organizational culture to facilitate knowledge sharing and to obtain full benefit from the lessons learned is one of the key elements of RO (Ortiz et al., 2004). This is important because changes in the culture of a given organization do not happen overnight; and requires among other things extensive and appropriate meetings and training (Ortiz et al., 2004). Accordingly, the following hypothesis is formulated:

H4: A positive significant relationship exists between personalization knowledge sharing strategy and results orientation.

\section{Knowledge Sharing Strategies and Transparency as an Organizational Excellence Pillar}

It is known that a main responsibility of any government is achieving welfare and responding to its citizens' needs. In recent years, for reasons of public interests, a bulk of knowledge became widely accessible (Yao et al., 2007; Zhou, 2004) and many governments have worked to increase openness and transparency in their actions (Bertot, et al., 2010; Yao et al., 2007; Zhou, 2004). One of the motivations to do that is the increased demands for transparency for stimulus funds (Lamont, 2009) and the use of them, detection of anti-competitive behaviors and the growing demands for accountability (Kleinschmidt, 2009). Therefore, a main challenge that confronts government organizations is accessing to right information and managing their most valuable resources, which are knowledge 
based, in a transparent manner (Kleinschmidt, 2009; Ghosh \& Ghosh, 2009).

In the organization-public relationship literature, transparency is often identified as openness (Rawlins, 2008). "Transparency" is the third organizational excellence pillar that is defined by the Award guide (2009) as providing all interested parties with the sufficient opportunity to see and know the related information and decisions including the justifications of making them, the responsible agents on these decisions and the resulted outcomes. Transparency construct was measured by the questionnaire items (29-33) which were developed based on the previous definition, mystery shopper form especially transparency section and other related previous studies (such as Bertot, et al., 2010; Kleinschmidt, 2009; Yao et al., 2007).

On the organizational level, some argue that transparency and the successful deployment of KM programs are strongly associated (Yao et al., 2007). Cormican \& O'Sullivan (2003) found that structured forms help generate and codify organizational problems and increased transparency and traceability. Maier \& Remus (2001) called for improving the handling of existing knowledge in documents to improve transparency. Bertot, et al., (2010) concluded that information and communication technologies and egovernment promote openness and transparency. Similarly, Van (2002) found that ICT tools help to address local needs, support decentralization of authority and build transparency. Therefore, some researchers argue that technology should be seen as part of the solution, rather than a problem or cost that can be cut back easily (Thomson, 2010) because these tools provide valuable transparency to the employee when other employees use them (Kleinschmidt, 2009). Thus, the following hypothesis is developed:

H5: A positive significant relationship exists between codification knowledge sharing strategies and transparency.

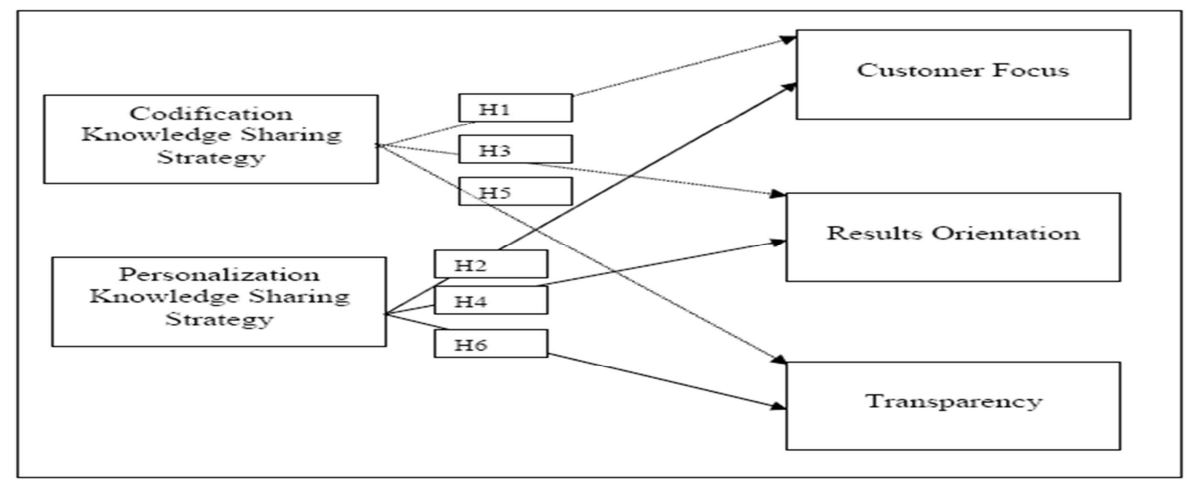

Figure 1. Research Suggested Model and Hypotheses

On the other hand, others called for improving the handling of existing knowledge in people's heads to improve transparency (Maier \& Remus, 2001). To create transparency, Lafarge Management aligned the KS culture with internal company programs to promote collaboration and communities of practice (Perrin et al., 2006).
Similarly, Kleinschmidt (2009) mentioned that many enterprise social tools allow people to easily collaborate either physically or virtually and do their job well within the overarching goal of promoting cross-team and cross-department sharing to promote transparency. Therefore, the following hypothesis is developed: 
H6: A positive significant relationship exists between personalization knowledge sharing strategies and transparency.

While some of these individual efforts have received considerable attention, the issue of whether KS strategies have influences on each of $\mathrm{OE}$ pillars has not been widely considered; specifically in public organizations in Jordan. Therefore, this paper tries to explore the previous untapped influences. Figure (1) depicts the suggested research model and hypotheses.

\section{Methodology}

\section{Population and Sample}

This empirical study employs a questionnaire approach designed to collect data for testing the validity of the model and research hypotheses. The population in this study is the four winning public organizations of King Abdullah II Award for Excellence in
Government Performance and Transparency in Jordan in the fourth cycle $(2008 / 2009)$. These organizations are: Ministry of Planning and International Cooperation, Ministry of Finance, Investment Unit in Social Security Corporation and Development and Employment Fund.

The main reason behind this selection is that all of the selected organizations present specialized training courses for their employees in KM subject and the pillars of OE. Besides that, evaluation results of the award declared that these organizations have KM strategies, customer focus, results orientation and transparency. So these organizations can be viewed as a source of learning for the other public organizations in Jordan that seek to enhance their KS strategies and their $\mathrm{OE}$ in general. More specifically, this study may have special importance for other public organizations that look forward to winning the Award in the next cycles.

\section{Table 1. Respondents Characteristics}

\begin{tabular}{|c|c|c|c|}
\hline Variable & Class & Frequency & Percent \\
\hline \multirow{3}{*}{ Gender } & Female & 80 & 41.9 \\
\hline & Male & 111 & 58.1 \\
\hline & Total & 191 & 100 \\
\hline \multirow{5}{*}{ Age } & more than 50 & 3 & 1.6 \\
\hline & $41-50$ & 50 & 26.2 \\
\hline & $31-40$ & 87 & 45.5 \\
\hline & 30 years or less & 51 & 26.7 \\
\hline & Total & 191 & 100 \\
\hline \multirow{4}{*}{ Experience } & 5 years or less & 43 & 22.5 \\
\hline & 6-10 years & 59 & 30.9 \\
\hline & 11 years or more & 89 & 46.6 \\
\hline & Total & 191 & 100 \\
\hline \multirow{5}{*}{$\begin{array}{l}\text { Education } \\
\text { Level }\end{array}$} & $\begin{array}{c}\text { Secondary school or } \\
\text { less }\end{array}$ & 8 & 4.2 \\
\hline & College & 23 & 12 \\
\hline & Bachelors & 105 & 55.0 \\
\hline & Higher education & 55 & 28.8 \\
\hline & Total & 191 & 100 \\
\hline
\end{tabular}


A simple random sample composed of 500 subjects $(50 \%$ of the study population) was selected in this study. Descriptive statistics for the 191 respondents are provided in table 1. 58.1 percent of the respondents are males and 45.5 percent of the respondents are between 31 to 40 years old. Nearly half of the respondents had been with their organizations for 11 years or more. 55 percent hold Bachelor degree.

\section{Data Collection}

To test the research model and the hypotheses, a total of 500 surveys were distributed and the anonymous questionnaires were requested to be completed by employees working in the four selected organizations in Jordan who are familiar with the topic of this study.

Table 2: Independent Factor Loadings, Eigenvalues, Variance Explained, Reliability, Mean and Standard Deviation

\begin{tabular}{|c|c|c|}
\hline Items/Constructs & CKSS & PKSS \\
\hline Alpha Cronpach & 0.854 & 0.843 \\
\hline Mean & 4.218 & 3.866 \\
\hline Standard Deviation & 0.578 & 0.751 \\
\hline Eigenvalues & 3.773 & 4.393 \\
\hline Variance explained & 53.90 & 62.750 \\
\hline $\begin{array}{l}\text { The organization believes that the utilization of technology-based knowledge sharing } \\
\text { tools is vital for the success of explicit knowledge sharing process. }\end{array}$ & 0.731 & \\
\hline $\begin{array}{l}\text { The organization provided the needed information infrastructure to facilitate explicit } \\
\text { knowledge sharing process. }\end{array}$ & 0.758 & \\
\hline $\begin{array}{l}\text { The organization concerns of documenting and codifying the organizational explicit } \\
\text { knowledge (such as researches, practical cases and problems that have been solved) } \\
\text { in specific knowledge repositories that can be referred to when needed. }\end{array}$ & 0.676 & \\
\hline $\begin{array}{l}\text { To facilitate explicit knowledge sharing process, the organization uses one or more of } \\
\text { the following means (Internet and intranet with their capabilities such as E-mail, } \\
\text { instant messages, knowledge sharing software, etc.... }\end{array}$ & 0.635 & \\
\hline $\begin{array}{l}\text { There are specialists' staff concern of storing and codifying the employees' explicit } \\
\text { knowledge. }\end{array}$ & 0.771 & \\
\hline $\begin{array}{l}\text { The organization takes into consideration intellectual property rights to maximize } \\
\text { the value of its organizational explicit knowledge. }\end{array}$ & 0.763 & \\
\hline $\begin{array}{l}\text { The explicit knowledge sharing strategy, the organization uses, facilitates the } \\
\text { providing of the routine services. }\end{array}$ & 0.792 & \\
\hline $\begin{array}{l}\text { The organization believes that encouraging human-based knowledge sharing tools } \\
\text { are vital for the success of tacit knowledge sharing process. }\end{array}$ & & 0.787 \\
\hline $\begin{array}{l}\text { The tacit knowledge sharing strategy, the organization uses, facilitates the providing } \\
\text { of distinguished and innovative services. }\end{array}$ & & 0.782 \\
\hline $\begin{array}{l}\text { Besides the formal interactions, the organization also provides opportunities for } \\
\text { informal interactions to facilitate the exchange of tacit knowledge. }\end{array}$ & & 0.783 \\
\hline $\begin{array}{l}\text { The organization adopts policies and procedures to facilitate tacit knowledge } \\
\text { exchange between the individuals and the groups via lectures and seminars, etc.... }\end{array}$ & & 0.763 \\
\hline $\begin{array}{l}\text { The organizational incentives system supports the individuals' contributions in tacit } \\
\text { knowledge sharing process. }\end{array}$ & & 0.790 \\
\hline $\begin{array}{l}\text { The organization facilitates the reach to the organization's experts and specialists to } \\
\text { get the benefit of their knowledge. }\end{array}$ & & 0.792 \\
\hline $\begin{array}{l}\text { The organization concerns of developing its employee's knowledge sharing personal } \\
\text { skills such as communication and discussion skills to enable their tacit knowledge } \\
\text { sharing process. . }\end{array}$ & & 0.846 \\
\hline
\end{tabular}


The questionnaire was pre-tested to ensure readability and validity before distribution. Follow-up letters, emails and phone calls were done a week later to appeal for participation. The study questionnaire includes 36 items measure codification knowledge sharing strategy, personalization knowledge sharing strategy, customer focus, results orientation and transparency (see tables 2,3). The study employs a short form items measures by a five-point Likert-type scale ranging from 1 (strongly disagree) to 5 (strongly agree). The questionnaire was distributed to explore the perceptions of each respondent related to the implementation of each construct in his organization. Of the 210 returned surveys, 191 were complete in all independent and dependent variables, giving us a 38.20 percent usable response rate. Using the 191 responses, we evaluated the validity of all constructs in the study using a factor analysis and found that all the constructs were valid.

Table 3: Dependent Factor Loadings, Eigenvalues, Variance Explained, Reliability, Mean and Standard Deviation

\begin{tabular}{|c|c|c|c|}
\hline Items/ Constructs & CF & RO & TR \\
\hline Alpha Cronpach & 0.910 & 0.913 & 0.903 \\
\hline Mean & 4.405 & 4.364 & 4.140 \\
\hline Standard Deviation & 0.5849 & 0.6545 & 0.7410 \\
\hline Eigenvalues & 4.908 & 4.202 & 3.349 \\
\hline Variance explained & 61.356 & 70.031 & 66.981 \\
\hline $\begin{array}{l}\text { The organization is distinguished by adopting core values } \\
\text { which focus on serving service recipients. }\end{array}$ & 0.703 & & \\
\hline $\begin{array}{l}\text { The organization identifies the priorities and makes the plans } \\
\text { that aim to improve the levels of the service recipients' } \\
\text { satisfaction. }\end{array}$ & 0.784 & & \\
\hline $\begin{array}{l}\text { The organization is distinguished by developing the service of } \\
\text { the service recipients. }\end{array}$ & 0.798 & & \\
\hline $\begin{array}{l}\text { The organization collaborates with its service recipients via } \\
\text { one or more of the following methods (complaints box, } \\
\text { surveys, free line, website, etc....). }\end{array}$ & 0.813 & & \\
\hline $\begin{array}{l}\text { The organization informs service recipients about its services } \\
\text { via one or more of the following communication methods } \\
\text { (website, brochures, media, etc....). }\end{array}$ & 0.784 & & \\
\hline $\begin{array}{l}\text { The organization has put indicators to be used in measuring } \\
\text { service recipients' satisfaction. }\end{array}$ & 0.818 & & \\
\hline $\begin{array}{l}\text { The organization concerns of collecting information about the } \\
\text { needs and expectations of its service recipients to use it in } \\
\text { enhancing its services. }\end{array}$ & 0.809 & & \\
\hline $\begin{array}{l}\text { The organization concerns of hidden shopper's report and } \\
\text { tries to enhance its performance and resolving the un } \\
\text { accepted points in it. }\end{array}$ & 0.751 & & \\
\hline $\begin{array}{l}\text { The organization is distinguished by adopting core values } \\
\text { which focus on achieving the best results. }\end{array}$ & & 0.786 & \\
\hline $\begin{array}{l}\text { The organization concerns with identifying the preferred } \\
\text { results (goals) the organization intends to achieve as a part of } \\
\text { its strategy. }\end{array}$ & & .8200 & \\
\hline $\begin{array}{l}\text { The organization planned and developed integrated } \\
\text { methodologies (such as developing work procedures, and }\end{array}$ & & .8020 & \\
\hline
\end{tabular}




\begin{tabular}{|c|c|c|}
\hline $\begin{array}{l}\text { providing suitable training courses for its employees) to } \\
\text { achieve its current and future goals. }\end{array}$ & & \\
\hline $\begin{array}{l}\text { The organization applies and implements the methodologies } \\
\text { in a systemic way. }\end{array}$ & .8540 & \\
\hline $\begin{array}{l}\text { The organization follows and reviews its strategic plan } \\
\text { implementation and achievements, and its performance to } \\
\text { verify the achievement of the preferred results. }\end{array}$ & .8740 & \\
\hline $\begin{array}{l}\text { The organization concerns measuring the advancement in } \\
\text { achieving the organizational goals by utilizing the suitable } \\
\text { performance indicators (quantitative and/or qualitative). }\end{array}$ & 0.880 & \\
\hline $\begin{array}{l}\text { Transparency is considered a core value that the organization } \\
\text { is concerned about distributing and enforcing it. }\end{array}$ & & 0.855 \\
\hline $\begin{array}{l}\text { The organization adopts clear policies aim to achieve } \\
\text { transparency and equal opportunities in all the decisions } \\
\text { related to employees affairs (selection, promotion, transfer, } \\
\text { performance evaluation, training, incentives, etc...). }\end{array}$ & & 0.852 \\
\hline $\begin{array}{l}\text { The organization followed a clear methodology in evaluating } \\
\text { suppliers to ensure the effectiveness of their procurements } \\
\text { processes. }\end{array}$ & & 0.845 \\
\hline $\begin{array}{l}\text { The organization concerns problem solving and decision } \\
\text { making based on the actual and documented information. }\end{array}$ & & 0.865 \\
\hline $\begin{array}{l}\text { The organization implements accurate and clear procedures in } \\
\text { executing its budget and auditing the financial processes and } \\
\text { the organization's accounts. }\end{array}$ & & 0.656 \\
\hline
\end{tabular}

\section{Analysis}

The data collected is analyzed using SPSS version 15. Statistical analysis followed interrelated steps. First, factor analysis using Varimax rotation was used to extract constructs and determine variance explained. The results of the factor analysis revealed five constructs. Those results have factor loadings that ranged from 0.635 to 0.880 . Tables 2,3 describe the results of factor analysis. Rows 3 and 4 of the tables show some descriptive parameters for each of the factors.

The reliability, assessed through the Cronbach Alpha, was greater than 0.70 for all the factors ranging from 0.854 to 0.913 ; thus providing an adequate level of reliability. Tables 2,3 show the factor loadings, eigenvalues and variance explained by the five factors. To test the construct validity, convergent and discriminant validity analyses were performed. Results indicate that the loadings and average variance extracted (AVE) for all the constructs are above the acceptable level. The loadings and AVE of the constructs higher than .60 and .50 respectively are considered good (Thakur \& Summey, 2007). The results indicate that all of the constructs under investigation surpass the acceptable level showing good convergent validity.

The associated survey items from each respondent were averaged to arrive at an aggregated score for each factor. Then Pearson's correlation analysis was adopted to check the multicollinearity by identifying correlations equal to or greater than 0.70 . Finally, these factors were entered into multiple regression models.

\section{Results}

Table 4 shows the correlation matrix. No high correlations between the independent variables were found. Correlations between these variables were $<0.70$ with $p$-values $<$ 0.01 . However, the computed variable 
inflation factors (VIFs) -which indicate the levels of multicollinearity with 1.00 indicating little or no multicollinearityranged from 1.61-3.23, which are acceptable as 10.0 is the cut-off score for acceptable VIF
(Hair, et al., 1995). So, since all the assumptions of regression were tested and no problem occurred, performing multiple regression analysis can be done.

\section{Table 4. Correlation Matrix}

\begin{tabular}{|c|c|c|c|c|c|}
\hline & CKSS & PKSS & CF & RO & TR \\
\hline CKSS & \multirow[t]{5}{*}{1} & $0.648^{* *}$ & $0.565^{* *}$ & $0.630^{* *}$ & $0.578^{* *}$ \\
\hline PKSS & & \multirow{4}{*}{$\begin{array}{l}1 \\
.\end{array}$} & $0.522^{* *}$ & $0.601^{* *}$ & $0.555^{* *}$ \\
\hline $\mathbf{C F}$ & & & 1 & $0.818^{* *}$ & $0.568^{* *}$ \\
\hline RO & & & & \multirow[t]{2}{*}{1} & $0.666^{* *}$ \\
\hline TR & & & & & 1 \\
\hline
\end{tabular}

** Correlation is significant at the 0.01 level (2-tailed).

As mentioned before, it is assumed that there are positive linear relationships between the codification knowledge sharing strategies, personalization knowledge sharing strategies and each of the organizational pillars (customer focus, results orientation and transparency). Then three multiple regression models were used for testing the study's hypotheses. Results in Table 5 indicate that each of the hypotheses that were tested for significance is found to be significant in explaining each of the dependent constructs (customer focus, results orientation and transparency) as mentioned below:

CKSS (standardized $\mathrm{b}=0.390, \mathrm{p}<.01$ ) and PKSS ( $b=0.269, p<.01)$ were found to be predictors of CF. Thus, the first and the second hypotheses are supported. Total Variance explained by the Model $=36.1 \%$. Regression equation for the obtained model is:

$\mathrm{CF}=1.930+0.390(\mathrm{CKSS})+0.269(\mathrm{PKSS})$.
H3 and H4 are also proved since CKSS (standardized $\mathrm{b}=0.415, \mathrm{p}<.01$ ) and PKSS (b $=0.332, \mathrm{p}<.01$ ) were found to be predictors of RO. Total Variance explained by the Model $=46.0 \%$. Following is the regression equation for the obtained model:

$\mathrm{RO}=1.268+0.415(\mathrm{CKSS})+0.332(\mathrm{PKSS})$.

As CKSS (standardized $b=0.377, p<.01$ ) and PKSS $(b=0.310, p<.01)$ were found to be predictors of transparency; H5 and H6 are also accepted. Total Variance explained by the Model $=39.0 \%$. Regression equation for the obtained model is:

$\mathrm{TR}=0.919+.377(\mathrm{CKSS})+0.310(\mathrm{PKSS})$.

The regression results and the total variance explained by the models are presented in Table 5. If we examine the reached results obtained from the regression analysis, it is found that the degree to which the researched organizations implement CKSS and PKSS will have a positive influence on each of CF, RO, and TR. 
Table 5. Results of Multiple Regression Analysis

\begin{tabular}{|c|c|c|c|c|c|c|c|c|c|}
\hline $\begin{array}{l}\text { Multiple } \\
\text { Regression } \\
\text { Model }\end{array}$ & $\begin{array}{l}\text { Dependent } \\
\text { Variable }\end{array}$ & $\mathbf{R}^{2}$ & $\begin{array}{c}\text { F- } \\
\text { value }\end{array}$ & $\begin{array}{l}\text { Independent } \\
\text { Variable }\end{array}$ & $\begin{array}{r}\text { Stan } \\
\text { CoG } \\
\text { Erro }\end{array}$ & $\begin{array}{l}\text { Un- } \\
\text { lardized } \\
\text { Beta } \\
\text { fficient } \\
\text { td. B }\end{array}$ & $\begin{array}{l}\text { Standardized } \\
\text { Beta } \\
\text { Coefficient }\end{array}$ & r-value & Sig \\
\hline \multirow{3}{*}{1} & \multirow{3}{*}{ CF } & \multirow{3}{*}{0.361} & \multirow{3}{*}{53.108} & (Constant) & 1.930 & .252 & & 7.668 & 0.000 \\
\hline & & & & CKSS & .395 & .077 & 0.390 & 5.095 & 0.000 \\
\hline & & & & PKSS & .210 & .060 & 0.269 & 3.516 & 0.001 \\
\hline \multirow{3}{*}{2} & \multirow{3}{*}{ Ro } & \multirow{3}{*}{0.460} & \multirow{3}{*}{80.15} & (Constant) & 1.268 & .259 & & 4.89 & 0.000 \\
\hline & & & & CKSS & .469 & .080 & 0.415 & 5.891 & 0.000 \\
\hline & & & & PKSS & .289 & .061 & 0.332 & 4.713 & 0.000 \\
\hline \multirow{3}{*}{3} & \multirow{3}{*}{ TR } & \multirow{3}{*}{0.390} & \multirow{3}{*}{60.113} & (Constant) & .919 & .311 & & 2.950 & 0.004 \\
\hline & & & & CKSS & .483 & .096 & 0.377 & 5.041 & 0.000 \\
\hline & & & & PKSS & .306 & .074 & 0.310 & 4.144 & 0.000 \\
\hline
\end{tabular}

\section{Results Discussion}

The general purpose of this study is to investigate the relationships between codification and personalization knowledge sharing strategies on organizational excellence pillars -customer focus, results orientation and transparency- in the researched organizations. The suggested research model and the hypotheses of this study are supported. The results show that organizations concern with implementing codification and personalization knowledge sharing strategies yields positive influences on customer focus. Besides that, when the respondents were asked to ascertain the degree to which knowledge sharing strategies positively influence each of $\mathrm{OE}$ pillars, their responses supported the obtained results as can be inferred from the percents in table 6 .

On CKSS side, these results became consistent with some prior studies, such as Nakata et al. (2008); Ferrell et al. (2010); Ailawadi et al. (2009); Bigné, et al. (2008). On PKSS side, the results reached are compatible with other studies results, such as Nakata et al. (2008); Lee and Choi (2003); Tillquist (2000); Shibata \& Kodama (2007).

The third research hypothesis tests whether a positive significant relationship exists between CKSS and results orientation. The study has reported a positive relationship between the two variables. The reached results disagree with some prior researches who found no influence (Brynjolfsson and Hitt, 2000; Dedrick et al., 2003; and Singh \& Zollo, 1998). But our results are consistent with other studies which found a positive relationship between the both (such as Ortiz et al., 2004; Broadbent et al., 2003). Besides, testing the fourth research hypothesis declared that PKSS positively influences results orientation. These results coincide with Ortiz et al., (2004). The last two hypotheses $\mathrm{H} 5$ and $\mathrm{H} 6$ of this research when tested uncovered that positive influences exist between KS strategies and TR. Similar results were found by other previous researchers, such as Bertot, et al. (2010); Yao et al. (2007); Perrin et al. (2006); Cormican \& O'Sullivan (2003).

It is important to examine the implications of this study. The results of this study could encourage public organizations working with information and knowledge resource aspects in strategic decisions and resource allocation particularly in adopting supportive CKSS and PKSS to enhance their OE. This is especially important as KS and OE represent a serious commitment that is not a short-term plan which requires collaborative efforts at the intra and interorganizational levels. KS strategies should put emphasis on how knowledge is used in order to efficiently enhance RO and TR. But prior to the development of a KS strategy, organizations 
need to measure the KS practices. The questionnaire of this study can be adopted and utilized by the organizations themselves as a diagnostic tool that can scan the founded practices and map the gaps to be considered and resolved. On the external organizational environment level, community surveys and needs analysis should be conducted on a regular basis to identify customers needs and enhance services.

Table 6. Knowledge Sharing Strategies and Organizational Excellence

\begin{tabular}{|c|c|c|c|c|c|c|c|c|c|c|}
\hline \multirow{2}{*}{ Statement } & \multicolumn{2}{|c|}{$\begin{array}{c}\text { Strongly } \\
\text { agree }\end{array}$} & \multicolumn{2}{|c|}{ Agree } & \multicolumn{2}{|c|}{ Uncertain } & \multicolumn{2}{|c|}{ Disagree } & \multicolumn{2}{|c|}{$\begin{array}{l}\text { Stron } \\
\text { gly } \\
\text { disagr } \\
\text { ee }\end{array}$} \\
\hline & 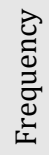 & 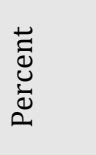 & 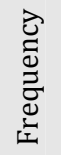 & 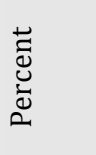 & 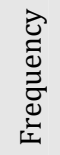 & 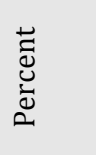 & 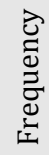 & 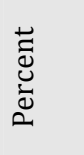 & 毒 & 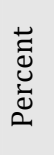 \\
\hline $\begin{array}{l}\text { The implementation of knowledge } \\
\text { sharing strategies in the organization } \\
\text { helps in focusing on the service } \\
\text { recipients and their satisfaction. }\end{array}$ & 67 & 35.1 & 85 & 44.5 & 35 & 18.3 & & 0.5 & 2 & 1.0 \\
\hline $\begin{array}{l}\text { The implementation of knowledge } \\
\text { sharing strategies in the organization } \\
\text { helps in orienting toward achieving } \\
\text { the preferred results for the } \\
\text { organization. }\end{array}$ & 62 & 32.5 & 82 & 42.9 & 40 & 20.9 & & 2.6 & 1 & 0.5 \\
\hline $\begin{array}{l}\text { The implementation of knowledge } \\
\text { sharing strategies in the organization } \\
\text { helps in achieving transparency. }\end{array}$ & 63 & 33.0 & 76 & 39.8 & 39 & 20.4 & & 4.7 & 3 & 1.6 \\
\hline
\end{tabular}

Moreover, management should focus on embedding KS into daily activities to encourage organizational members to share their best practices and lessons learned regarding customer services, organizational objectives and preferred results. In addition, organizations are recommended to establish an organizational memory and motivate their employees to contribute to it and use it when needed to avoid re-inventing the wheel case. Most obvious is that managers should consider strengthening their organizations IT capability. New technologies such as internet, intranet and computer technologies that support customer information handling and related work flows could be crucial to KS facilitation. Furthermore adoption emerging social networking sites have the potential to supplement traditional face-to-face social networks. Another vital element for the successful adoption of $\mathrm{CF}, \mathrm{RO}$ and $\mathrm{TR}$ is training. Therefore, interactive CDs and induction workshops on the previous topics should include staff at all managerial levels to enable change management efforts. Forming internal cross-functional teams and task teams comprised of members from different departments and representative service recipients is expected to enable the dynamic KS.

\section{Limitations and Future Research}

This study also has its limitations. Therefore, findings of this study should be interpreted in light of these limitations. First, this is a preliminary study of the influence of KS strategies on achieving $\mathrm{OE}$ in distinguished public organizations in Jordan. We recommend that similar research is necessary in the other public organizations to validate the findings of this study. As they 
may hold different and potentially conflicting viewpoints, the study could also be conducted from the perspectives of employees, citizens or politicians. In addition, this study is carried out by empirically investigating some public organizations in the Jordanian environment. Potential cultural limitation should be noted and future research is suggested in different cultural contexts, from developed and developing countries, to generalize or modify the concepts. However, this study does not consider the roles played by organizational factors; future studies might gain additional insights by exploring these factors. Limitations of this study also include the need for more research into the KM cycle.

\section{Acknowledgements}

The authors would like to thank Petra University in Jordan for financially supporting this research.

\section{References}

Ailawadi, K. L., Beauchamp, J. P. Donthu, N., Gauri, D. K. \& Shankar, V. (2009). "Communication and Promotion Decisions in Retailing: A Review and Directions for Future Research," Journal of Retailing, 85 (1), 42-55.

Alavi, M. \& Leidner, D. (2002). KM Systems: Issues, Challenges and Benefits, in Barnes, S. (Ed.). KM Systems: Theory and Practice, Oxford, Alden Press.

Alavi, M. \& Leidner, D. E. (2001). "Review: Knowledge Management and Knowledge Management Systems: Conceptual Foundations and Research Issues," MIS Quarterly, 25 (1), 107-36.

Al-Faouri, A. H. (2010). "A Supportive Knowledge Sharing Climate to Enable IT/Business Strategic Alignment," Jordan Journal of Business Administration, 6 (1), 119140.

Alwis, R. S. \& Hartmann, E. (2008). “The Use of Tacit Knowledge Within Innovative
Companies: Knowledge Management in Innovative Enterprises," Journal of Knowledge Management, 12 (1), 133-147.

Awad, E. \& Ghaziri, H. (2004). 'Knowledge Management,' Pearson Education, New Jersey.

'Baldridge National Quality Program: Criteria for Performance Excellence,' Date of Access 6/Aug/2010.

Http://Www.Quality.Nist.Gov/Publiciteria.Cf $\mathrm{m}$.

Behery, M. H. (2008). 'Leadership, Knowledge Sharing, and Organizational Benefits Within UAE,' Journal of American Academy of Business, 12 (2), 227-237.

Bertot, J. C., Jaeger, P. T. \& Grimes, J. M. (2010). "Using Icts to Create a Culture of Transparency: E-Government and Social Media as Openness and Anti-Corruption Tools for Societies," Government Information Quarterly, 27 (3), 264-271.

Bigné, J. E. , Aldas, J. \& Andreu, L. (2008). "B2B Services: IT Adoption in Travel Agency Supply Chains," Journal of Services Marketing, 22 (6), 454-464.

Broadbent, M., Mcdonald, M. \& Hunter, R. (2003). 'Letter from Marianne Broadbent, Mark Mcdonald, and Richard Hunter,' Harvard Business Review, 81 (6), 10.

Brynjolfsson, E. \& Hitt, L. M. (2000). “Beyond Computation: Information Technology, Organizational Transformation and Business Performance," Journal of Economic Perspectives, 14 (4), 23-48.

Carr, N. G. (2003). “ IT Doesn't Matter, "Harvard Business Review, 81 (5), 4149.

Chaung, S.-H. (2004). "A Resource-Based Perspective on Knowledge Management Capability and Competitive Advantage: an Empirical Investigation," Expert Systems with Applications, 27 (3),459-465. 
Choi, B. \& Lee, H. (2002). "Knowledge Management Strategy and Its Link to Knowledge Creation Process," Expert Systems with Applications, 23 (3), 173-87.

Cormican, K. O. \& O'Sullivan, D. (2003). “A Collaborative Knowledge Management Tool for Product Innovation Management," International Journal of Technology Management, 26 (1), 53 - 67.

Dalkir, K., Wiseman, E., Shulha, M. \& Mcintyre, S. (2007). "An Intellectual Capital Evaluation Approach in a Government Organization," Management Decision, 45 (9),1497-1509.

Darroch, J. (2003). "Developing a Measure of Knowledge Management Behaviors and Practices," Journal of KM, 7 (5), 41-54.

Davenport, T. H. \& Prusak, L. (1998). Working Knowledge: How Organizations Manage What They Know, Boston, HBS Press, MA.

Day, G. S. (2003). "Creating a Superior Customer-Relating Capability," MIT Sloan Management Review, 44 (3), 77-82.

De Smet, A., Loch, M. \& Schaninger, B. (2007). 'The Links Between Profits and Organizational Performance,' Mckinsey Quarterly, 3, 6-9.

Dedrick, J., Gurbaxani, V. \& Kraemer, K. L. (2003). "Information Technology and Economic Performance: a Critical Review of the Empirical Evidence," ACM Computing Surveys, 35 (1),1-28.

Deshpande, R., Farley, J. U. \& Webster, F. E. (1993). "Corporate Culture, Customer Orientation, and Innovativeness in Japanese Firms: a Quadrad Analysis," Journal of Marketing, 57 (1), 23-37.

Drucker, P. F. (1954). The Practice of Management, New York, Harper and Row.
Drucker P. F. (1993). Post-Capitalist Society, Oxford, Butterworth-Heinemann.

Earl, M. (2001). "Knowledge Management Strategies: Toward Taxonomy," Journal of Management Information Systems, 18 (1), 215-233.

Eftekharzadeh, R. (2008). 'Knowledge Management Implementation in Developing Countries: an Experimental Study,' Review of Business, 28 (3), 44-59.

Fatt, C. K. \& Khin, E. W. S. (2010). "The SocialTechnical View of Knowledge Management in Services Industries," Journal of Social Sciences 6 (2), 256-264.

Ferrell, L. , Gonzalez-Padron, T. L. \& Ferrell, O. C. (2010). "An Assessment of the Use of Technology in the Direct Selling Industry," Journal of Personal Selling \& Sales Management, 30 (2), 157-165.

Firestone, J. M. \& Mcelroy, M. W. (2005). "Doing Knowledge Management," the Learning Organization, 12 (5), 189-212.

Frazier, M. A. \& Swiss, J. E. (2008). "Contrasting Views of Results-Based Management Tools from Different Organizational Levels," International Public Management Journal, 11 (2), 214-235.

Gatignon, H. \& Xuereb, J.-M. (1997). "Strategic Orientation in the Firm and New Product Performance," Journal of Marketing Research, 34 (1), 77-90.

Ghosh, M. \& Ghosh, I. (2009). "ICT and Information Strategies for a Knowledge Economy: the Indian Experience," Program, 43 (2), 187-201.

Hair, J. F., Anderson, R. F., Tatham, R. L. \& Black, W. C. (1995). Multivariate Data Analysis with Readings, Englewood Cliffs, NJ, Prentice Hall. 
Hansen, M. T., Nohria N. \& Tierney, T. (1999). "What's Your Strategy For Managing Knowledge?," Harvard Business Review, 77 (2), 106-116.

Hesselink, M. \& van den Assem, F. (2002). "Building People and Organizational Excellence: the Start Service Excellence Program," Managing Service Quality, 12 (3), 139-145.

Hu, M.-L. (2009). "Knowledge Sharing and Innovative Service Behavior Relationship: Guanxi as Mediator," Social Behavior and Personality, 37 (7), 977-992.

Huang, J.-W. \& Li, Y.-H. (2009). "The Mediating Effect of Knowledge Management on Social Interaction and Innovation Performance," International Journal of Manpower, 30 (3), 285-301.

Huang, L. (2006). "Building up a B2B ECommerce Strategic Alliance Model under an Uncertain Environment for Taiwan's Travel Agencies," Tourism Management, 27 (6), 1308-1320.

Huysman, M. \& Wulf, V. (2006). "IT to Support Knowledge Sharing in Communities: Toward a Social Capital Analysis," Journal of Information Technology, 21 (1), 40-51.

Kikoski, C. K. \& Kikoski, J. F. (2004). The Inquiring Organization: Tacit Knowledge, Conversation, and Knowledge Creation Skills for 21st-Century Organizations, Praeger, Westport, CT and London.

Kleinschmidt, J. (2009). "Interface : CrossCompany Knowledge Sharing; How Enterprise Social Networking Transforms the Workplace," Information Management, 19 (8), 56.

Lamont, J. (2009). "KM Provides Transparency for Stimulus Funds," KM World, July/August, 10-22. Lee, H. \& Choi, B. (2003). "Knowledge Management Enablers, Processes, and Organizational Performance: an Integrative
View and Empirical Examination," Journal of Management Information Systems, 17 (2), 115-152.

Lin, H.-F. (2007). "Knowledge Sharing and Firm Innovation Capability: an Empirical Study," International Journal of Manpower, 28 (3/4), 315-332.

Maier, R. (2004). Knowledge Management Systems: Information and Communication Technologies for Knowledge Management, Berlin, Springer-Verlag.

Maier, R. \& Remus, U. (2001). "Towards a Framework for Knowledge Management Strategies: Process Orientation as Strategic Starting Point," Proceedings of the Hawai'i International Conference on System Sciences, January 3-6, Maui, Hawaii.

Mason, D. \& Pauleen, D. J. (2003). "Perceptions of Knowledge Management: a Qualitative Analysis," Journal of Knowledge Management, 7 (4), 38-48.

Mentzas, G. (2001). 'A Holistic Approach to Realizing the Full Value of Your Knowledge Assets,' Knowledge Management Review, 4 (3), 10-11.

Moore, M. H. (1995). Creating Public Value Strategic Management in Government, Cambridge, M, Harvard University Press.

Mukherji, S. (2005). 'Knowledge Management Strategy in Software Services Organisations: Straddling Codification and Personalization,' IIMB Management Review, September, 33-39.

Nakata, C., Zhu, Z. \& Kraimer, M. L. (2008). "The Complex Contribution of Information Technology Capability to Business Performance," Journal of Managerial Issues, 20 (4), 485-506.

Nonaka, I. \& Takeuchi, H. (1995). The Knowledge Creating Company; How Japanese Companies Create the Dynamics of Innovation, New York, Oxford University Press. 
Nonaka, I., Toyama, R. \& Boysiere, P. (2001). 'A Theory of Organizational Knowledge Creation: Understanding the Dynamic Process of Creating Knowledge,' in Dierkes, M., Antal, A., Child, J. And Nonaka, I. (Eds), Handbook Of Organizational Learning And Knowledge, New York, Oxford University Press, Pp. 491-517.

Ortiz, E. F., Kuyama, S., Münch, W., \& Tang, G. (2004). "Implementation of Results-Based Management in the United Nations Organizations: Part I: Series on Managing for Results in the United Nations System," JIU/REP/2004/6, 24pgs.

Osborne, M. (2004). "Making the Most of the Best: Formulating a Knowledge Management Strategy for a Government Advisory Body," Australian Journal of Public Administration, 63 (3), 43-52.

Pan, S. L. \& Leidner, D. E. (2003). "Bridging Communities of Practice with Information Technology in Pursuit of Global Knowledge Sharing," Journal of Strategic Information Systems, 12 (1), 71-88.

Perrin, A., Vidal, P. \& Mcgil, J. (2006). "Valuing Knowledge Sharing in Lafarge," Knowledge and Process Management, 13 (1), 26 - 34.

Pollitt, C. \& Bouckaert, G. (2000). 'Public Management Reform - a Comparative Analysis,' Oxford, Oxford University Press.

Rapp, A., Raja, A. \& Lukas P. F. (2008). "The Sales Force Technology-Performance Chain: the Role of Adaptive Selling and Effort," Journal of Personal Selling \& Sales Management, 28 (4), 335-350.

Rawlins, B. L. (2008). "Measuring the Relationship between Organizational Transparency and Employee Trust," Public Relations Journal, 2 (2).

Rhodes, J., Lok, P., Hung, R. Y.-Y \& Fang, S.-C. (2008). "An Integrative Model of Organizational Learning and Social Capital on Effective Knowledge Transfer and Perceived
Organizational Performance," Journal of Workplace Learning, 20 (4), 245-258.

Riege, A. (2005). "Three-Dozen KnowledgeSharing Barriers Managers Must Consider," Journal of Knowledge Management, 9 (3), 1835.

Saito, A., Umemoto, K. \& Ikeda, M. (2007). “A Strategy-Based Ontology of Knowledge Management Technologies," Journal of Knowledge Management, 11 (1), 97-114.

Schotte, T. (2003)."Customer Knowledge Management: How Does My Customer Look and Feel?," in Beerli, A. J. Et Al. (Eds), Knowledge Management and Networked Environments, New York, American Management Association, 17-38.

Sen, S., Raghu, T. S. \& Vinze, A. (2010). "Demand Information Sharing in Heterogeneous IT Services Environments," Journal of Management Information Systems, 26 (4), 287-316.

Shibata, T. \& Kodama, M. (2007). "Knowledge Integration Through Networked Strategic Communities: Two Case Studies in Japan," Business Strategy Series, 8 (6), 394-400.

Singh, H. \& Zollo, M. (1998). "The Impact of Knowledge Codification, Experience Trajectories and Integration Strategies on the Performance of Corporate Acquisitions," Proceeding of the Conference of the Academy of Management in San Diego, August 1998.

Skandia. (1994). 'Visualising Intellectual Capital in Skandia,' Supplement to Annual Report.

Smith, A. D. (2004). "Knowledge Management Strategies: a Multi-Case Study," Journal of Knowledge Management, 8 (3), 6-16.

Song, S. (2002). 'An Internet Knowledge Sharing System,' Journal of Computer Information Systems, 42 (3), 25-30. 
Srivastava, K., Mishra, S. \& Pandey, S. (2008). 'Organizational Excellence: Total Quality Management,' SCMS Journal of Indian Management, 5 (4), 16-25.

Steyn, C. \& Kahn, M. (2008). "Towards the Development of A Knowledge Management Practices Survey for Application in Knowledge Intensive Organizations," South African Journal of Business Management, 39 (1), 45-53.

Sunassee, N. N. \& Sewry, D. A. (2002)." A Theoretical Framework for Knowledge Management Implementation," in: Kotze, P., Venter, L., and Barrow, M (Eds.). Enablement through Technology. Proceedings of SAICSIT 2002, Annual Research Conference of the South African Institute of Computer Scientists and Information Technologists, Pretoria: SAICSIT.

Thakur, R. \& Summey, J. (2007). 'E-Trust: Empirical Insights into Influential Antecedents,' Marketing Management Journal , 17 (2), 67-81.

The Guide of King Abdullah II Award for Excellence in Government Performance and Transparency in Jordan, (2009). Date of Access 6/Aug/2010. Http://Www.Kaa.Jo/PDF/Awardguide.Pdf

Thomson, R. (2010). 'IT Must Now Rise to the Challenge of Delivering Transparent Government,' Computer Weekly, 6/8, 6-6.

Tillquist, J. (2000). "Institutional Bridging: How Conceptions of IT-Enabled Change Shape the Planning Process," Journal of Management Information Systems 20 (1), 179-228.

Treasury Board of Canada. (2003). TBS Management Accountability Framework, Government of Canada, Ottawa.

Try, D. \& Radnor, Z. (2007). “Developing an Understanding of Results-Based Management through Public Value Theory," the
International Journal of Public Sector Management, 20 (7), 655-673.

Van Der Velden, M. (2002). "Knowledge Facts, Knowledge Fiction: the Role of Icts in Knowledge Management for Development," Journal of International Development, 14 (1), 25-37.

Widén-Wulff, G. \& Suomi, R. (2007). "Utilization of Information Resources for Business Success: the Knowledge Sharing Model," Information Resources Management Journal, 20 (1), 46-68.

Www.Kaa.Jo/Sites/Kaaen/Awardaward/Def ault.Aspx, Date of Access 6/Aug/2010.

Yang, J.-T. (2007). "The Impact of Knowledge Sharing on Organizational Learning and Effectiveness," Journal of Knowledge Management, 11 (2), 83-90.

Yao, L. J., Kam, T. H. Y. \& Chan, S. H. (2007). "Knowledge Sharing in Asian Public Administration Sector: the Case of Hong Kong," Journal of Enterprise Information Management, 20 (1), 51-69.

Zhou, A. Z. (2004). "Managing Knowledge Strategically: a Comparison of Managers' Perceptions Between the Private and Public Sector in Australia," Journal of Information and Knowledge Management, 3 (3), 18-29. 